\title{
Understanding the Stability of $\mathrm{MAPbBr}_{3}$ versus $\mathrm{MAPbl}_{3}$ : Suppression of Methylammonium Migration and Reduction of Halide Migration
}

\author{
Lucie McGovern, Moritz H. Futscher, Loreta A. Muscarella, and Bruno Ehrler*
}

Cite This: J. Phys. Chem. Lett. 2020, 11, 7127-7132

Read Online

ABSTRACT: Solar cells based on metal halide perovskites often show excellent efficiency but poor stability. This degradation of perovskite devices has been associated with the migration of mobile ions. $\mathrm{MAPbBr}_{3}$ perovskite materials are significantly more stable under ambient conditions than $\mathrm{MAPbI}_{3}$ perovskite materials. In this work, we use transient ion drift to quantify the key characteristics of ion migration in $\mathrm{MAPbBr}_{3}$ perovskite solar cells. We then proceed to compare them with those of $\mathrm{MAPbI}_{3}$ perovskite solar cells. We find that in $\mathrm{MAPbBr}_{3}$, bromide migration is the main process at play and that contrary to the case of $\mathrm{MAPbI}_{3}$, there is no evidence for methylammonium migration. Quantitatively, we find a reduced activation energy, a reduced diffusion coefficient, and a reduced concentration for halide ions in $\mathrm{MAPbBr}_{3}$ compared

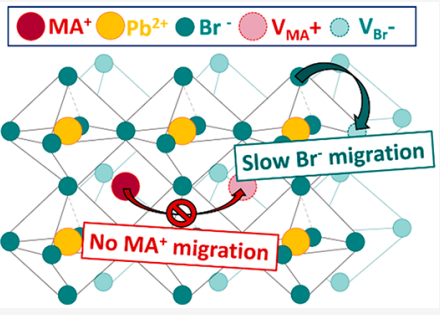
to $\mathrm{MAPbI}_{3}$. Understanding this difference in mobile ion migration is a crucial step in understanding the enhanced stability of $\mathrm{MAPbBr}_{3}$ versus $\mathrm{MAPbI}_{3}$.

$\mathrm{P}$ erovskite solar cells, with solution-based, cheap synthesis methods and a rapid increase in power conversion efficiency, are a promising candidate for future solar cells. Record efficiencies of $25.2 \%$ and $29.2 \%$ for single-junction and perovskite/silicon tandem configurations ${ }^{1}$ are already competitive with those of existing technologies. However, a major hurdle for commercialization remains, the degradation of highefficiency perovskite materials under a range of environmental factors. Humidity, ${ }^{2-4}$ illumination, $^{5-8}$ and thermal stress ${ }^{8,9}$ have all been shown to degrade the power conversion efficiency of the devices over time. Ion migration has been identified as one of the main drivers for degradation. ${ }^{10}$

The stability of metal halide perovskites is compositiondependent. For example, $\mathrm{MAPbI}_{3}$ is more sensitive to all of the environmental factors mentioned above than $\mathrm{MAPbBr}_{3}{ }^{11}$ Some mechanisms have been proposed to explain this stability enhancement. In terms of material degradation, decomposition studies link the enhanced stability of $\mathrm{MAPbBr}_{3}$ to a predominance of the reversible decomposition reaction $\mathrm{CH}_{3} \mathrm{NH}_{3} \mathrm{PbX}_{3}(\mathrm{~s}) \rightleftharpoons \mathrm{CH}_{3} \mathrm{NH}_{2}(\mathrm{~g})+\mathrm{HX}(\mathrm{g})+\mathrm{PbX}_{2}(\mathrm{~s})$, compared to the irreversible decomposition pathway $\mathrm{CH}_{3} \mathrm{NH}_{3} \mathrm{PbX}_{3}(\mathrm{~s}) \rightleftharpoons \mathrm{NH}_{3}(\mathrm{~g})+\mathrm{CH}_{3} \mathrm{X}(\mathrm{g})+\mathrm{PbX}_{2}(\mathrm{~s})$, in contrast to $\mathrm{MAPbI}_{3}$ that exhibits both types of decomposition. $^{12}$ More recently, the decomposition reaction $4 \mathrm{CH}_{3} \mathrm{NH}_{3} \mathrm{PbX}_{3}+\mathrm{O}_{2} \rightleftharpoons 4 \mathrm{PbX}_{2}+2 \mathrm{X}_{2}+2 \mathrm{H}_{2} \mathrm{O}+4 \mathrm{CH}_{3} \mathrm{NH}_{2}$ has been shown to slow upon substitution of iodide with bromide. $^{13}$

In terms of ion migration, theoretical predictions for $\mathrm{MAPbBr}_{3}$ suggest that the stronger $\mathrm{Pb}-\mathrm{Br}$ bond ${ }^{14-17}$ could increase the halide ion defect formation energy ${ }^{18}$ and thereby suppress the degradation caused by ion migration. Migration of the bulky $\mathrm{MA}^{+}$ion might also be inhibited by steric hindrance, because the lattice constant of $\mathrm{MAPbBr}_{3}$ is smaller, ${ }^{19,20}$ and/or by stronger hydrogen bonding to the surrounding $\mathrm{Pb}-\mathrm{Br}_{6}$ octahedra. However, though ion migration is one of the causes of degradation of perovskite devices, ${ }^{10}$ many of its aspects remain poorly understood. It is in fact unclear if the ion migration is reduced in $\mathrm{MAPbBr}_{3}$ compared to $\mathrm{MAPbI}_{3}$, and which aspect of the mobile ions is affected.

Here we use transient ion drift (TID) to quantify the characteristics of mobile ions in $\mathrm{MAPbBr}_{3}$. We identify the nature of mobile ions and their activation energy, concentration, and diffusion coefficients and compare them to the characteristics of mobile ions in $\mathrm{MAPbI}_{3} \cdot{ }^{21}$ We find that the concentration of mobile bromide ions is on average 8 times lower than in their iodide counterpart in $\mathrm{MAPbI}_{3}$, and that the bromide ions diffuse $\sim 3$ times slower, with an activation energy that is slightly lower than that of the migration of iodide. Halide migration is therefore greatly affected when tuning the halide composition. However, the halide composition does not affect solely the halide migration, as one might expect. A striking difference between the iodide and bromide perovskites lies in the methylammonium $\left(\mathrm{MA}^{+}\right)$migration. We measure a high density of migrating $\mathrm{MA}^{+}$ions in the iodide perovskite. In stark contrast, $\mathrm{MA}^{+}$migration is inhibited in the bromide perovskite. This difference might be one of the keys to their higher structural stability, because the A-site cations have been shown to be critical for the structural properties of

Received: June 12, 2020

Accepted: August 7, 2020

Published: August 7, 2020 


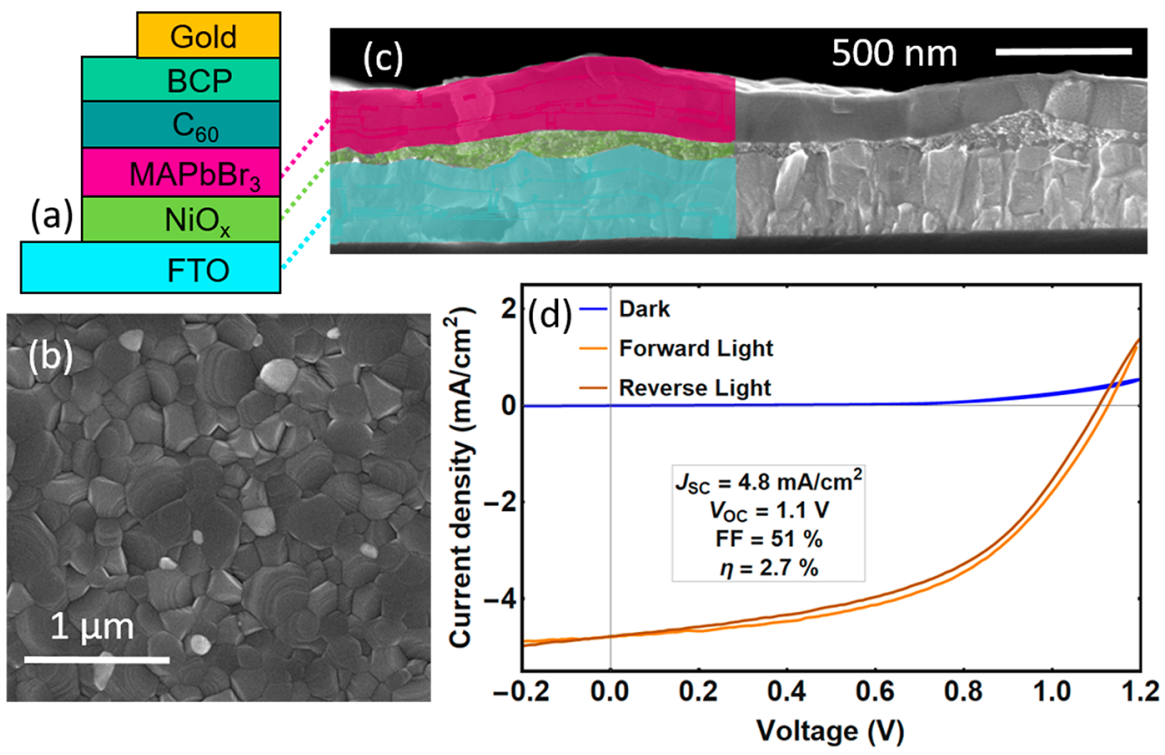

Figure 1. Inverted $\mathrm{MAPbBr}_{3}$ device characteristics. (a) Solar cell architecture of the full device, with the $\mathrm{MAPbBr}_{3}$ film sandwiched between a hole transport layer of $\mathrm{NiO}_{x}$ and an electron transport layer of $\mathrm{C}_{60}$ and BCP. A fluoride tin oxide (FTO) bottom electrode and a gold top electrode complete the device, allowing for the extraction of the holes and electrons. (b) Top view SEM image of the $\mathrm{MAPbBr}_{3}$ perovskite layer showing 200-500 nm grains. (c) SEM cross-sectional image of the $\mathrm{MAPbBr}_{3}$ perovskite layer on top of $\mathrm{FTO}$ and $\mathrm{NiO}_{x^{*}}$ (d) Current-voltage characteristics measured in the dark and light, with a scan speed of $10 \mathrm{mV} \mathrm{s}^{-1}$.
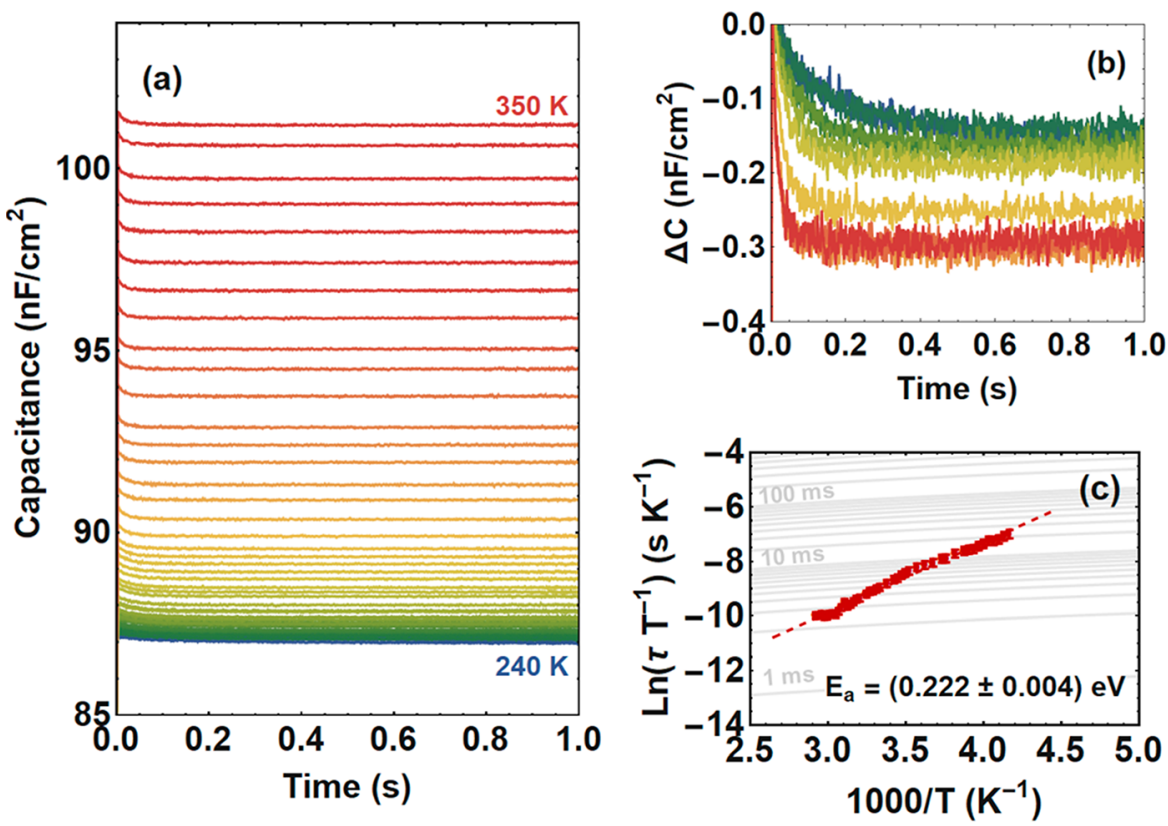

Figure 2. (a) Capacitance transient measurements of a $\mathrm{MAPbBr}_{3}$ solar cell measured in the dark, with a DC voltage of $0 \mathrm{~V}$ and an $\mathrm{AC}$ voltage of 10 $\mathrm{mV}$ at $10^{4} \mathrm{~Hz}$, after applying a pulse of $1.1 \mathrm{~V}$ for $1 \mathrm{~s}$. (b) Relative difference in capacitance $\Delta C=C(t)-C_{2.5} \mathrm{~ms}$ for the capacitance transients between 240 and $340 \mathrm{~K}$. (c) Arrhenius plot showing the activation energy derived from this measurement.

perovskites. $^{22,23}$ We hence assign the higher stability of the $\mathrm{MAPbBr}_{3}$ perovskite in part to slower and fewer mobile halide ions, and in part to the suppression of $\mathrm{MA}^{+}$cation migration.

We use TID, a capacitance-based technique, to measure the mobile ions in the perovskite diodes. While there are several techniques for measuring ion migration, TID allows for discrimination between anion and cation migration and independently measures the number density $\left(N_{\text {ion }}\right)$ and diffusion coefficient $(D)$ of mobile ions. With temperaturedependent measurements of the capacitance transients, TID further quantifies the activation energy $\left(E_{\mathrm{a}}\right)$ for ions that migrate. A more detailed discussion of the technique can be found in the sections $S 1 a$ and $S 1 b$ of the Supporting Information and in ref 24.

We fabricate a full solar cell as the diode for capacitance measurements and choose suitable contact layers such that the main contribution to the ion drift comes from the perovskite layer. The architecture of the solar cell is a planar $\mathrm{p}-\mathrm{i}-\mathrm{n}$ junction as shown in Figure 1a. For a direct comparison with our reported results on $\mathrm{MAPbI}_{3}{ }^{21}$ we use the same transport layers: $\mathrm{NiO}_{x}$ as the hole transport layer and $\mathrm{C}_{60}$ and $\mathrm{BCP}$ as electron transport layers. We also prepare the $\mathrm{MAPbBr}_{3}$ 
perovskite using a similar antisolvent technique, modified slightly to yield films of similar thickness and grain size. Figure $1 \mathrm{~b}$ shows a top view scanning electron microscopy (SEM) image of such a $\mathrm{MAPbBr}_{3}$ perovskite film formed on top of $\mathrm{NiO}_{x}$. The film features a good surface coverage and an apparent grain size (as estimated by SEM morphology) between 200 and $500 \mathrm{~nm}$, comparable to the average 300 $\mathrm{nm}$ size of $\mathrm{MAPbI}_{3}$ perovskite grains from our previous report. Cross-sectional SEM shows layers of $180 \pm 20 \mathrm{~nm}$ as shown in Figure 1c, also comparable to our $\mathrm{MAPbI}_{3}$ solar cells. With $\mathrm{MAPbBr}_{3}$, the device shows a power conversion efficiency of $2.7 \%$ (Figure 1d), a value close to that of previous work with this simple architecture ${ }^{25}$ (see section S2). There is little hysteresis between the forward and reverse scans.

To measure the capacitance transients of the $\mathrm{MAPbBr}_{3}$ solar cell device, we apply a voltage bias close to the built-in bias of the device $(1.1 \mathrm{~V})$ for $1 \mathrm{~s}$ to redistribute the ions. After the bias is released, the ions move back to the contacts and we record the resulting capacitance transients (Figure 2a; see section S1 for experimental details). The relative capacitance change is presented in Figure $2 \mathrm{~b}$, with one transient every $10 \mathrm{~K}$. We also repeat the whole measurement for a different filling voltage $(1.4 \mathrm{~V})$, as is presented in Figure S2 (see section S3).

The transients in panels a and $\mathrm{b}$ of Figure 2 show a small and rapid exponential decrease on the order of $10 \mathrm{~ms}$, followed by a flat baseline when the system has reached its steady state. In TID of p-type semiconductors, we assign positive trends to the migration of cations and negative trends to the migration of anions. Hall measurements ${ }^{26}$ suggest the p-type nature of $\mathrm{MAPbBr}_{3}$. Additionally, both time-of-flight secondary ion mass spectroscopy (ToF-SIMS) ${ }^{27}$ and nanoprobe X-ray fluorescence $(\mathrm{Nano}-\mathrm{XRF})^{28}$ measure a time evolution of the spatial bromide concentration in $\mathrm{MAPbBr}_{3}$ single crystals. We thus assign the negative feature present in the whole temperature range to bromide migration. As there is no apparent positive feature in the capacitance transients, we conclude that there is no or very little cation migration. If present at all, the mobile cation concentration must be below $1.5 \times 10^{13} \mathrm{~cm}^{-3}$, the sensitivity threshold for this measurement (see section S1a). This is in contrast with our previous results for $\mathrm{MAPbI}_{3}$, for which we found a combination of migration from the iodide $\left(\mathrm{I}^{-}\right)$anion and the $\mathrm{MA}^{+}$cation, ${ }^{21}$ both with significant concentrations of mobile ions, $10^{15} \mathrm{~cm}^{-3}$ for $\mathrm{I}^{-}$and $10^{16} \mathrm{~cm}^{-3}$ for $\mathrm{MA}^{+}$.

Substituting bromide for iodide in the $\mathrm{MAPbX}_{3}(\mathrm{X}=\mathrm{I}$ or $\mathrm{Br}$ ) framework thus leads to a significant suppression of $\mathrm{MA}^{+}$ migration. This effect was already hypothesized as a consequence of the structural contraction of the $\mathrm{MAPbBr}_{3}$ framework $^{13}$ and/or the stronger hydrogen bonding between the lead halide octahedra and the $\mathrm{MA}^{+}$cation. ${ }^{13,29}$ With regard to this second hypothesis, we note that although it has been evoked multiple times in the literature, the experimental data do not match but instead show an equal strength of hydrogen bonds whether using $\mathrm{X}=\mathrm{I}, \mathrm{Br}$, or $\mathrm{Cl}$ in $\mathrm{MAPbX}_{3}{ }^{30-32} \mathrm{We}$ therefore infer that the lattice contraction is the origin of the suppression of $\mathrm{MA}^{+}$migration, an assessment that matches the trend found in density functional theory (DFT) modeling. ${ }^{33}$ This means that the lattice unit cell size makes a major contribution to the enhanced stability of these systems. This finding sheds light on the possible origin of the increased stability of complex mixed-cation/mixed-halide perovskites compared to pure-halide materials, as well as the origin of the higher stability of compressed perovskites. In the future, a systematic study of ion migration versus pressure could determine the specific compression factor, i.e., the specific unit cell size, necessary to suppress cation migration.

To quantify bromide migration, we fit each capacitance transient to extract $\tau$, the lifetime of the process (see section S1a). Determined over many temperatures, the extracted lifetimes are used in an Arrhenius plot to obtain $E_{\mathrm{a}}$ and $D$, as shown in Figure $2 c$ and Figure S2c. Using the equation for mobile ion density (see eq 3 in section S1d), $N_{\text {ion }}$ is also measured. The results are listed in Table 1, averaging over two different filling voltages each for two solar cells.

\section{Table 1. Characteristics of Mobile Ions in $\mathrm{MAPbBr}_{3}$ Averaged from Four Individual Measurements}

$\begin{array}{ccc}\begin{array}{c}\text { activation } \\ \text { energy }(\mathrm{eV})\end{array} & \begin{array}{c}\text { diffusion coefficient at } 300 \mathrm{~K} \\ \left(\mathrm{~cm}^{2} \mathrm{~s}^{-1}\right)\end{array} & \begin{array}{c}\text { concentration of mobile } \\ \text { ions }\left(\mathrm{cm}^{-3}\right)\end{array} \\ 0.25 \pm 0.05 & (8.4 \pm 3.9) \times 10^{-10} & (1.3 \pm 0.7) \times 10^{14}\end{array}$

To understand the increased stability of $\mathrm{MAPbBr}_{3}$ compared to that of $\mathrm{MAPbI}_{3}$, we compare changes in ion migration (Figure 3). We have already presented the data for iodide migration in $\mathrm{MAPbI}_{3}$ in previous work, ${ }^{21}$ and it is reproduced here for comparison.

Our initial hypothesis was an increase in the activation energy for bromide migration in $\mathrm{MAPbBr}_{3}$, due to lead forming a stronger bond with bromide than iodide. ${ }^{14-17}$ Our results indicate the reverse trend, with an activation energy slightly decreasing from $0.29 \mathrm{eV}$ for iodide migration to 0.25 $\mathrm{eV}$ for bromide migration. These values are close to experimental activation energies found by temperaturedependent hysteresis measurements. ${ }^{34}$ We note that they differ, however, from DFT calculations by Lin et al., ${ }^{18}$ a difference that may arise from the approximation their work uses, of a low-temperature phase with orthorhombic structure. The decrease in activation energy can potentially be rationalized by the smaller size of the bromide ion, possibly reducing the steric hindrance during the transition state of migration for bromide. Meggiolaro et $\mathrm{al}^{35}$ decompose the activation energy into the migration energy barrier $\Delta^{\ddagger} H^{\circ}$ and a DFE (defect formation energy) term, the latter accounting for the energy required to form the defect undergoing the jump. Using their finding that the lower limit for the DFE term to vanish is reached for $\sim 250 \mathrm{~nm}$ grains, we can neglect DFE in our study. What these results serve to show is that the activation energy for ions to migrate is the result of an interplay of competing effects, in this case the steric hindrance versus the bond strength. These numbers can further help us to understand the halide migration mechanism. In fact, molecular dynamics (MD) modeling shows that in both $\mathrm{MAPbI}_{3}$ and $\mathrm{MAPbBr}_{3}$, the lowest activation energy for halide migration is through a vacancy-mediated hopping mechanism. ${ }^{34}$ The activation energies we measure are similar to the MDsimulated values, which helps us in elucidating the mechanism for halide migration in $\mathrm{MAPbBr}_{3}$. A vacancy-mediated hopping pathway is likely dominating, as is the case in $\mathrm{MAPbI}_{3}{ }^{36,37}$

We turn now to the comparison of the diffusion coefficients, which can be expressed through the following equation: ${ }^{24}$

$$
D=D_{0} \exp \left(\frac{-\Delta^{\ddagger} G^{\circ}}{k_{\mathrm{B}} T}\right)=\frac{v_{0} d^{2}}{6} \exp \left(\frac{\Delta^{\ddagger} S^{\circ}}{k_{\mathrm{B}}}\right) \exp \left(\frac{-\Delta^{\ddagger} H^{\circ}}{k_{\mathrm{B}} T}\right)
$$



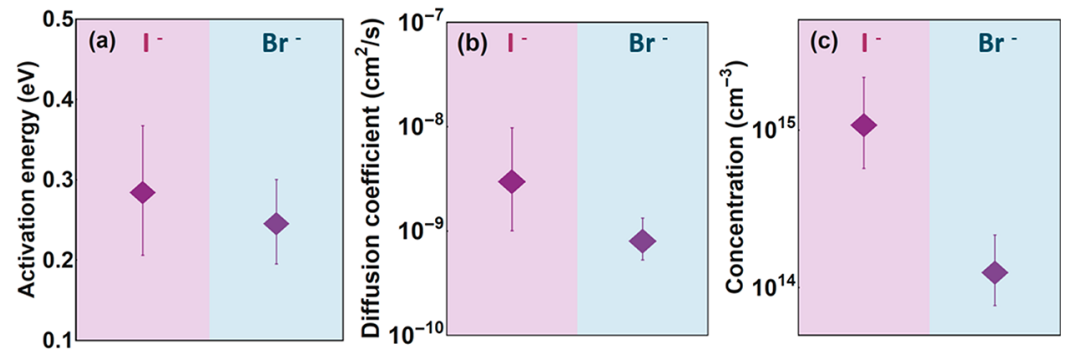

Figure 3. Comparison of mobile ions in $\mathrm{MAPbBr}_{3}$ and $\mathrm{MAPbI}_{3}$ showing (a) a reduced activation energy for bromide migration, (b) a reduced diffusion coefficient for bromide migration (at $300 \mathrm{~K}$ ), and (c) a reduced density of bromide mobile ions. Error bars are the standard deviations of the weighted means.

where $\Delta^{\ddagger} G^{\circ}, \Delta^{\ddagger} H^{\circ}$, and $\Delta^{\ddagger} S^{\circ}$ are the changes in Gibbs free energy, enthalpy, and entropy of activation, respectively, for a single ion migration step, $k_{\mathrm{B}}$ is the Boltzmann constant, $\nu_{0}$ is the attempt-to-escape frequency, and $d$ is the jump distance. We choose to follow the usual formalism that refers to the change in Gibbs free enthalpy as activation energy $E_{\mathrm{a}}$.

We measure a bromide diffusion coefficient at $300 \mathrm{~K}$ of $\sim 1$ $\times 10^{-9} \mathrm{~cm}^{2} \mathrm{~s}^{-1}, 3$ times less than that of iodide, at $3 \times 10^{-9}$ $\mathrm{cm}^{2} \mathrm{~s}^{-1}$. Following eq 1 , if we combine a reduction in both the bromide diffusion coefficient $D(\mathrm{Br})$ and the bromide activation energy $E_{\mathrm{a}}(\mathrm{Br})$, we find that either the attempt-to-escape frequency, $v_{0}(\mathrm{Br})$, the jump distance, $d(\mathrm{Br})$, or the entropy term, $\Delta S(\mathrm{Br})$, must decrease compared to their iodide counterparts $\left[v_{0}(\mathrm{I}), d(\mathrm{I})\right.$, and $\left.\Delta S(\mathrm{I})\right]$. The jump distance $d(\mathrm{Br})$ is probably shorter than $d(\mathrm{I})$ due to the smaller lattice constant in the bromide perovskite, with $[1.2 d(\mathrm{Br})]^{2} \simeq d(\mathrm{I})^{2}$. However, this change is counterbalanced by the increase in the attempt-to-escape frequency $v_{0}(\mathrm{Br})$, with $v_{0}(\mathrm{Br}) \simeq 1.5 v_{0}(\mathrm{I})$, a value that we derive from the Raman and FTIR blue-shifts when moving from iodide to bromide. ${ }^{30,31,38}$ This suggests that the entropy term decreases for bromide compared to iodide, i.e., that $\Delta S^{\circ}(\mathrm{Br})<\Delta S^{\circ}(\mathrm{I})$. Solution calorimetry measurements $^{39,40}$ for the perovskite formation reaction show that the enthalpic and entropic contributions are indeed of opposite directions for both $\mathrm{MAPbI}_{3}$ and $\mathrm{MAPbBr}_{3}$. Though of a different nature, the changes considered in refs 39 and 40 are about the entropy and enthalpy of reaction and not the entropy and enthalpy of activation; these results underline the importance of considering not only the enthalpic contribution but also the entropic contribution in determining the ion migration diffusion coefficient. Taken together, this means that even if the activation energy to migrate is lower for a bromide ion than for an iodide ion, the reduced diffusion coefficient suggests a smaller entropic gain for bromide migration, explaining the overall trend.

The third element that TID allows us to quantify is the concentration of mobile bromide ions. Here we measure an average concentration of $1.3 \times 10^{14} \mathrm{~cm}^{-3}$, i.e., 8 times lower than the average concentration of mobile iodide ions in $\mathrm{MAPbI}_{3}$, at $1.1 \times 10^{15} \mathrm{~cm}^{-3}$. The lower density of mobile bromide ions will reduce any ion-induced degradation in $\mathrm{MAPbBr}_{3}$. This lower density probably results from an increase in the energy to form bromide vacancies, which in turn decreases the number of bromide vacancies and thus reduces the number of sites to which bromide ions can migrate.

It is worth mentioning that the concentrations found in the literature still differ by many orders of magnitude, mainly due to the differences in the models used to interpret experimental data $^{41}$ (see section S1a). The results reported here are consistent with various experimental studies ${ }^{42-46}$ that show ion concentrations between $10^{14}$ and $10^{16} \mathrm{~cm}^{-3}$. Studies that report significantly higher ion concentrations typically assume a complete screening of the electric field in the perovskite. ${ }^{47}$

Comparing ion migration in $\mathrm{MAPbBr}_{3}$ and $\mathrm{MAPbI}_{3}$ thus results in a smaller amount of slower mobile bromide ions, and a striking absence of methylammonium migration. The reduction in ion mobile concentration for $\mathrm{MA}^{+}$is on the order of at least $10^{3}$, and on the order of 10 for $\mathrm{X}^{-}$. Taken together, these results suggest two independent mechanisms for the formation of either methylammonium or halide vacancies, or a combination of two independent mechanisms together with a joint mechanism, such as the one proposed by Walsh et al. for Schottky defects: nil $\rightarrow \mathrm{V}^{\prime}{ }_{\text {MA }}+\mathrm{V}^{\bullet}{ }_{\mathrm{X}}+\mathrm{MAX}^{48}$ Inhibiting these defect formation reactions is thus essential for enhancing the stability of the $\mathrm{MAPbBr}_{3}$ perovskite.

We use TID to provide a direct and reliable comparison of ion migration between $\mathrm{MAPbBr}_{3}$ and $\mathrm{MAPbI}_{3}$. Our finding is that the activation energy for bromide migration is reduced, contrary to simple bond strength considerations. Despite the reduced activation energy, the diffusion of halides is slower, presumably because of a lower entropic change for ion migration. We note that previously the focus has often been on activation energy when studying ion migration. We show that in addition to the activation energy, it is crucial to consider the entropy change during migration to understand the diffusion of mobile ions. We also find 8 times fewer halide ions migrating in $\mathrm{MAPbBr}_{3}$ than in $\mathrm{MAPbI}_{3}$, probably a consequence of the higher vacancy formation energy. Finally, we show that bromide substitution inhibits $\mathrm{MA}^{+}$migration, due to lattice contraction. This suppression of A-cation migration enhances the structural stability of pure-halide perovskites and could be further used as a tool for stabilization of more complex and efficient mixed-cation mixed-halide perovskites.

\section{ASSOCIATED CONTENT}

\section{(s) Supporting Information}

The Supporting Information is available free of charge at https://pubs.acs.org/doi/10.1021/acs.jpclett.0c01822.

Experimental details of device fabrication, electrical measurements, imaging of device, transient ion drift technique, and impedance and Mott-Schottky analysis; solar cell performance; and capacitance transients and Arrhenius plot for a filling voltage of $1.4 \mathrm{~V}$ (PDF) 


\section{AUTHOR INFORMATION}

\section{Corresponding Author}

Bruno Ehrler - Center for Nanophotonics, AMOLF, 1098 XG Amsterdam, The Netherlands; 0 orcid.org/0000-0002-53073241; Email: b.ehrler@amof.nl

\section{Authors}

Lucie McGovern - Center for Nanophotonics, AMOLF, 1098 XG Amsterdam, The Netherlands; @ orcid.org/0000-00017263-5249

Moritz H. Futscher - Center for Nanophotonics, AMOLF, 1098 XG Amsterdam, The Netherlands; ๑ orcid.org/00000001-8451-5009

Loreta A. Muscarella - Center for Nanophotonics, AMOLF, 1098 XG Amsterdam, The Netherlands; ๑ orcid.org/00000002-0559-4085

Complete contact information is available at:

https://pubs.acs.org/10.1021/acs.jpclett.0c01822

\section{Notes}

The authors declare no competing financial interest.

All data are available in the main text or the Supporting Information and will be provided on request.

\section{ACKNOWLEDGMENTS}

This work is part of the Dutch Research Council (NWO) and was performed at the research institute AMOLF. The work of L.M. and L.A.M. was supported by NWO Vidi Grant 016.Vidi.179.005, and the work of M.H.F. by NWO Project 15PR3202. The authors thank Erik Garnett and Eline Hutter for carefully reading and commenting on the manuscript.

\section{REFERENCES}

(1) https://www.nrel.gov/pv/cell-efficiency.html (accessed 202001-31).

(2) Christians, J. A.; Miranda Herrera, P. A.; Kamat, P. V. Transformation of the Excited State and Photovoltaic Efficiency of $\mathrm{CH}_{3} \mathrm{NH}_{3} \mathrm{PbI}_{3}$ Perovskite upon Controlled Exposure to Humidified Air. J. Am. Chem. Soc. 2015, 137, 1530-1538.

(3) Kye, Y.-H.; Yu, C.-J.; Jong, U.-G.; Chen, Y.; Walsh, A. Critical Role of Water in Defect Aggregation and Chemical Degradation of Perovskite Solar Cells. J. Phys. Chem. Lett. 2018, 9, 2196-2201.

(4) Marronnier, A.; Lee, H.; Lee, H.; Kim, M.; Eypert, C.; Gaston, J.P.; Roma, G.; Tondelier, D.; Geffroy, B.; Bonnassieux, Y. Critical Role of Water in Defect Aggregation and Chemical Degradation of Perovskite Solar Cells. Sol. Energy Mater. Sol. Cells 2018, 178, 179185.

(5) Yuan, H.; Debroye, E.; Janssen, K.; Naiki, H.; Steuwe, C.; Lu, G.; Moris, M.; Orgiu, E.; Uji-I, H.; De Schryver, F.; et al. Degradation of Methylammonium Lead Iodide Perovskite Structures through Light and Electron Beam Driven Ion Migration. J. Phys. Chem. Lett. 2016, 7, $561-566$.

(6) Xiang, Y.; Zhang, F.; He, J.; Lian, J.; Zeng, P.; Song, J.; Qu, J. Light-current induced acceleration of degradation of methylammonium lead iodide perovskite solar cells. J. Power Sources 2018, 384, 303-311.

(7) Nickel, N. H.; Lang, F.; Brus, V. V.; Shargaieva, O.; Rappich, J. Unraveling the Light-Induced Degradation Mechanisms of $\mathrm{CH}_{3} \mathrm{NH}_{3} \mathrm{PbI}_{3}$ Perovskite Films. Adv. Electron. Mater. 2017, 3, 1700158.

(8) Brunetti, B.; Cavallo, C.; Ciccioli, A.; Gigli, G.; Latini, A. On the Thermal and Thermodynamic (In)Stability of Methylammonium Lead Halide Perovskites. Sci. Rep. 2016, 6, 31896.

(9) Alberti, A.; Deretzis, I.; Mannino, G.; Smecca, E.; Sanzaro, S.; Numata, Y.; Miyasaka, T.; La Magna, A. Revealing a Discontinuity in the Degradation Behavior of $\mathrm{CH}_{3} \mathrm{NH}_{3} \mathrm{PbI}_{3}$ during Thermal Operation. J. Phys. Chem. C 2017, 121, 13577-13585.

(10) Nandal, V.; Nair, P. R. Predictive Modeling of Ion Migration Induced Degradation in Perovskite Solar Cells. ACS Nano 2017, 11, 11505-11512.

(11) Pont, S.; Bryant, D.; Lin, C.-T.; Aristidou, N.; Wheeler, S.; Ma, X.; Godin, R.; Haque, S. A.; Durrant, J. R. Tuning $\mathrm{CH}_{3} \mathrm{NH}_{3} \mathrm{~Pb}-$ $\left(\mathrm{I}_{1-\mathrm{x}} \mathrm{Br}_{\mathrm{x}}\right)_{3}$ Perovskite Oxygen Stability in Thin Films and Solar Cells. J. Mater. Chem. A 2017, 5, 9553-9560.

(12) Juarez-Perez, E. J.; Ono, L. K.; Maeda, M.; Jiang, Y.; Hawash, Z.; Qi, Y. Photodecomposition and Thermal Decomposition in Methylammonium Halide Lead Perovskites and Inferred Design Principles to Increase Photovoltaic Device Stability. J. Mater. Chem. A 2018, 6, 9604-9612.

(13) Aziz, A.; Aristidou, N.; Bu, X.; Westbrook, R. J. E.; Haque, S. A.; Islam, M. A. Understanding the Enhanced Stability of Bromide Substitution in Lead Iodide Perovskites. Chem. Mater. 2020, 32, 400409.

(14) Yoon, S. J.; Kuno, M.; Kamat, P. V. Shift Happens. How Halide Ion Defects Influence Photoinduced Segregation in Mixed Halide Perovskites. ACS Energy Lett. 2017, 2, 1507-1514.

(15) Yoon, S. J.; Stamplecoskie, K. G.; Kamat, P. V. How Lead Halide Complex Chemistry Dictates the Composition of Mixed Halide Perovskites. J. Phys. Chem. Lett. 2016, 7, 1368-1373.

(16) Szafranski, M.; Katrusiak, A. Mechanism of Pressure-Induced Phase Transitions, Amorphization, and Absorption-Edge Shift in Photovoltaic Methylammonium Lead Iodide. J. Phys. Chem. Lett. 2016, 7, 3458-3466.

(17) Jaffe, A.; Lin, Y.; Beavers, C. M.; Voss, J.; Mao, W. L.; Karunadasa, H. I. High-Pressure Single-Crystal Structures of 3D LeadHalide Hybrid Perovskites and Pressure Effects on their Electronic and Optical Properties. ACS Cent. Sci. 2016, 2, 201-202.

(18) Lin, C.; Li, S.; Zhang, W.; Shao, C.; Yang, Z. Effect of Bromine Substitution on the Ion Migration and Optical Absorption in $\mathrm{MAPbI}_{3}$ Perovskite Solar Cells. ACS Appl. Energy Mater. 2018, 1, 1374-1380.

(19) Noh, J. H.; Im, S. H.; Heo, J. H.; Mandal, T. N.; Seok, S. I. Chemical Management for Colorful, Efficient, and Stable InorganicOrganic Hybrid Nanostructured Solar Cells. Nano Lett. 2013, 13, $1764-1769$.

(20) Atourki, L.; Vega, E.; Marí, B.; Mollar, M.; Ait Ahsaine, H.; Bouabid, K.; Ihlal, A. Role of the Chemical Substitution on the Structural and Luminescence Properties of the Mixed Halide Perovskite Thin $\mathrm{MAPbI}_{3-\mathrm{x}} \mathrm{Br}_{\mathrm{x}}(0 \leq x \leq 1)$ Films. Appl. Surf. Sci. 2016, 371, 112-117.

(21) Futscher, M. H.; Lee, J. M.; McGovern, L.; Muscarella, L. A.; Wang, T.; Haider, M. I.; Fakharuddin, A.; Schmidt-Mende, L.; Ehrler, B. Quantification of Ion Migration in $\mathrm{CH}_{3} \mathrm{NH}_{3} \mathrm{PbI}_{3}$ Perovskite Solar Cells by Transient Capacitance Measurements. Mater. Horiz. 2019, 6, $1497-1503$

(22) Oranskaia, A.; Yin, J.; Bakr, O. M.; Brédas, J.-L.; Mohammed, O. F. Halogen Migration in Hybrid Perovskites: the Organic Cation Matters. J. Phys. Chem. Lett. 2018, 9, 5474-5480.

(23) Feldmann, S.; Macpherson, S.; Senanayak, S. P.; Abdi-Jalebi, M.; Rivett, J. P. H.; Nan, G.; Tainter, G. D.; Doherty, T. A. S.; Frohna, K.; Ringe, E.; et al. Photodoping through Local Charge Carrier Accumulation in Alloyed Hybrid Perovskites for Highly Efficient Luminescence. Nat. Photonics 2020, 14, 123-128.

(24) Futscher, M. H.; Gangishetty, M. K.; Congreve, D. N.; Ehrler, B. Quantifying Mobile Ions and Electronic Defects in PerovskiteBased Devices with Temperature-Dependent Capacitance Measurements: Frequency versus Time Domain. J. Chem. Phys. 2020, 152, 044202 .

(25) Hu, X.; Jiang, X.-F.; Xing, X.; Nian, L.; Liu, X.; Huang, R.; Wang, K.; Yip, H.-L.; Zhou, G. Wide-Bandgap Perovskite Solar Cells with Large Open-Circuit Voltage of $1653 \mathrm{mV}$ through Interfacial Engineering. Sol. RRL 2018, 2, 1800083.

(26) Musiienko, A.; Moravec, P.; Grill, R.; Praus, P.; Vasylchenko, I.; Pekarek, J.; Tisdale, J.; Ridzonova, K.; Belas, E.; Landová, L.; et al. 
Deep Levels, Charge Transport and Mixed Conductivity in Organometallic Halide Perovskites. Energy Environ. Sci. 2019, 12, 1413-1425.

(27) Ahmadi, M.; Muckley, E. S.; Ivanov, I. N.; Lorenz, M.; Li, X.; Ovchinnikova, O.; Lukosi, E. D.; Tisdale, J. T.; Blount, E.; Kravchenko, I. I.; et al. Environmental Gating and Galvanic Effects in Single Crystals of Organic-Inorganic Halide Perovskites. ACS Appl. Mater. Interfaces 2019, 11, 14722-14733.

(28) Luo, Y.; Khoram, P.; Brittman, S.; Zhu, Z.; Lai, B.; Ong, S. P.; Garnett, E. C.; Fenning, D. P. Direct Observation of Halide Migration and its Effect on the Photoluminescence of Methylammonium Lead Bromide Perovskite Single Crystals. Adv. Mater. 2017, 29, 1703451.

(29) El-Mellouhi, F.; Marzouk, A.; Bentria, E. T.; Rashkeev, S. N.; Kais, S.; Alharbi, F. H. Hydrogen Bonding and Stability of Hybrid Organic-Inorganic Perovskites. ChemSusChem 2016, 9, 2648-2655.

(30) Glaser, T.; Müller, C.; Sendner, M.; Krekeler, C.; Semonin, O. E.; Hull, T. D.; Yaffe, O.; Owen, J. S.; Kowalsky, W.; Pucci, A.; et al. Infrared Spectroscopic Study of Vibrational Modes in Methylammonium Lead Halide Perovskites. J. Phys. Chem. Lett. 2015, 6, 29132918.

(31) Leguy, A. M. A.; Goñi, A. R.; Frost, J. M.; Skelton, J.; Brivio, F.; Rodríguez-Martínez, X.; Weber, O. J.; Pallipurath, A.; Alonso, M. I.; Campoy-Quiles, M.; et al. Dynamic Disorder, Phonon Lifetimes, and the Assignment of Modes to the Vibrational Spectra of Methylammonium Lead Halide Perovskites. Phys. Chem. Chem. Phys. 2016, 18, 27051-27066.

(32) Svane, K. L.; Forse, A. C.; Grey, C. P.; Kieslich, G.; Cheetham, A. K.; Walsh, A.; Butler, K. T. How Strong is the Hydrogen Bond in Hybrid Perovskites? J. Phys. Chem. Lett. 2017, 8, 6154-6159.

(33) Azpiroz, J. M.; Mosconi, E.; Bisquert, J.; De Angelis, F. Defect Migration on Methylammonium Lead iodide and its Role in Perovskite Solar Cell Operation. Energy Environ. Sci. 2015, 8, 2118-2127.

(34) Meloni, S.; Moehl, T.; Tress, W.; Franckevičius, M.; Saliba, M.; Lee, Y. H.; Gao, P.; Nazeeruddin, M. K.; Zakeeruddin, S. M.; Rothlisberger, U.; Graetzel, M. Ionic Polarization-Induced CurrentVoltage Hysteresis in $\mathrm{CH}_{3} \mathrm{NH}_{3} \mathrm{PbX}_{3}$ Perovskite Solar Cells. Nat. Commun. 2016, 7, 10334.

(35) Meggiolaro, D.; Mosconi, E.; De Angelis, F. Formation of Surface Defects Dominates Ion Migration in Lead-Halide Perovskites. ACS Energy Lett. 2019, 4 (3), 779-785.

(36) Eames, C.; Frost, J. M.; Barnes, P. R. F.; O’Regan, B. C.; Walsh, A.; Islam, M. S. Ionic Transport in Hybrid Lead Iodide Perovskite Solar Cells. Nat. Commun. 2015, 6, 7497.

(37) Haruyama, J.; Sodeyama, K.; Han, L.; Tateyama, Y. FirstPrinciples Study of Ion Diffusion in Perovskite Solar Cell Sensitizers. J. Am. Chem. Soc. 2015, 137, 10048-10051.

(38) Ledinský, M.; Löper, P.; Niesen, B.; Holovský, J.; Moon, S.-J.; Yum, J.-H.; De Wolf, S.; Fejfar, A.; Ballif, C. Raman spectroscopy of Organic-Inorganic Halide Perovskites. J. Phys. Chem. Lett. 2015, 6, 401-406.

(39) Ivanov, I. L.; Steparuk, A. S.; Bolyachkina, M. S.; Tsvetkov, D. S.; Safronov, A. P.; Zuev, A. Y. Thermodynamics of Formation of Hybrid Perovskite-Type Methylammonium Lead Halides. J. Chem. Thermodyn. 2018, 116, 253-258.

(40) Ciccioli, A.; Latini, A. Thermodynamics and the Intrinsic Stability of Lead Halide Perovskites $\mathrm{CH}_{3} \mathrm{NH}_{3} \mathrm{PbX}_{3}$. J. Phys. Chem. Lett. 2018, 9, 3756-3765.

(41) Bertoluzzi, L.; Boyd, C.; Rolston, N.; Xu, J.; Prasanna, R.; O'Regan, B.; McGehee, M. Mobile Ion Concentration Measurement and Open-Access Band Diagram Simulation Platform for Halide Perovskite Solar Cells. Joule 2020, 4, 109-127.

(42) Birkhold, S. T.; Precht, J. T.; Liu, H.; Giridharagopal, R.; Eperon, G. E.; Schmidt-Mende, L.; Li, X.; Ginger, D. S. Interplay of Mobile Ions and Injected Carriers Creates Recombination Centers in Metal Halide Perovskites under Bias. ACS Energy Lett. 2018, 3, 12791286.

(43) Weber, S. A. L.; Hermes, I. M.; Turren-Cruz, S.-H.; Gort, C.; Bergmann, V. W.; Gilson, L.; Hagfeldt, A.; Graetzel, M.; Tress, W.;
Berger, R. How the Formation of Interfacial Charge Causes Hysteresis in Perovskite Solar Cells. Energy Environ. Sci. 2018, 11, 2404-2413.

(44) Reichert, S.; Flemming, J.; An, Q.; Vaynzof, Y.; Pietschmann, J.F.; Deibel, C. Ionic-Defect Distribution Revealed by Improved Evaluation of Deep-Level Transient Spectroscopy on Perovskite Solar Cells. Phys. Rev. Appl. 2020, 13, 034018.

(45) Caram, J.; García-Batlle, M.; Almora, O.; Arce, R. D.; Guerrero, A.; Garcia-Belmonte, G. Direct Observation of Surface Polarization at Hybrid Perovskite/Au Interfaces by Dark Transient Experiments. Appl. Phys. Lett. 2020, 116, 183503.

(46) Barboni, D.; De Souza, R. A. The Thermodynamics and Kinetics of Iodine Vacancies in the Hybrid Perovskite Methylammonium Lead Iodide. Energy Environ. Sci. 2018, 11, 3266-3274.

(47) Calado, P.; Telford, A. M.; Bryant, D.; Li, X.; Nelson, J.; O’Regan, B. C.; Barnes, P. R. F. Evidence for Ion Migration in Hybrid Perovskite Solar Cells with Minimal Hysteresis. Nat. Commun. 2016, 7, 13831.

(48) Walsh, A.; Scanlon, D. O.; Chen, S.; Gong, X. G.; Wei, S.-H. Self-Regulation Mechanism for Charged Point Defects in Hybrid Halide Perovskites. Angew. Chem., Int. Ed. 2015, 54, 1791-1794. 